- Identification marking of dentures is regulated by guidelines in several other countries.

- Within the UK, there are no specific guidelines or policies for civilian denture identification marking.

- The prevalence of denture marking in the UK is low.

- The overwhelming opinion of prosthodontic specialists within the UK supports the philosophy of denture marking as a routine procedure.

\title{
A survey of denture identification marking within the United Kingdom
}

\author{
C. A. Murray, ${ }^{1}$ P. T. Boyd ${ }_{1}{ }^{2}$ B. C. Young, ${ }_{1}^{3}$ S. Dhar ${ }_{1}^{4}$ M. Dickson ${ }^{5}$ and J. N. W. Currie ${ }^{6}$
}

\begin{abstract}
Aim To assess the attitudes of healthcare workers within the UK towards identification marking of removable prostheses, and quantify the frequency with which this is currently undertaken.

Design A postal questionnaire-based study.

Setting The study was undertaken within the UK between 2002 and 2006 and surveyed prosthodontists working in a wide range of clinical settings.
\end{abstract}

Subjects and methods Questionnaires were sent to two sample groups: 1. Specialists in prosthodontics registered on the GDC specialist list; 2. Nursing staff in elderly care homes within the locality of Glasgow.

Results Return rate of questionnaires from prosthodontic specialists was high, with 119 from 160 (74\%) completed and returned. 54.9\% of prosthodontic specialists carried out complete denture marking in their clinical practice and $40.9 \%$ undertook identification marking of partial removable prostheses. The vast majority (81.0\%) of specialists indicated that denture identification marking was a worthwhile procedure. Furthermore, $68.9 \%$ thought the introduction of some form of guideline would be beneficial. Differences in the frequency of denture marking existed between varying clinical environments. Denture marking was not undertaken by healthcare workers within any of the surveyed care homes.

Conclusion The overwhelming opinion of prosthodontic specialists within the UK promotes the use of denture marking as a routine procedure.

\footnotetext{
*Clinical Senior Lecturer/Honorary Consultant in Restorative Dentistry, Adult Dental Care, University of Glasgow Dental School and Hospital, 378 Sauchiehall Street, Glasgow, G2 3JZ; ${ }^{2}$ Senior House Officer, Department of Oral and Maxillofacial Surgery, Southern General Hospital, Glasgow, G51 4TF; ${ }^{3}$ Senior House Officer, Department of Prosthodontics, ${ }^{4}$ Senior House Officer, Department of Oral Surgery, ${ }^{5}$ Honorary Clinical Teacher in Restorative Dentistry, University of Glasgow Dental School and Hospital, 378 Sauchiehall Street, Glasgow, G2 3JZ; ${ }^{6}$ General Dental Practitioner, Glasgow, G15 6EG ${ }^{*}$ Correspondence to: Dr Colin A. Murray Email:c.murray@dental.gla.ac.uk
}

\section{Online article number E24}

Refereed Paper - accepted 24 April 2007

DOI: $10.1038 /$ bdj.2007.944

${ }^{\circledR}$ British Dental Journal 2007; 203: E24

\section{INTRODUCTION}

It is a well-documented practice to mark dentures with some means of identification. Although the rate of edentulousness is falling, ${ }^{1}$ the wearing of dentures will continue for a considerable time. ${ }^{2}$ There are several recognised benefits to identification marking of dentures. Principally, these can be considered as identification of the wearer or conversely, identification of the dentures themselves. The former would include identification of the wearer post mortem, including forensic crime scene analysis. The latter would include separation of the wearer's dentures from those of other individuals. This is particularly applicable for subjects in a residential or institutional care environment. Furthermore, denture identification would enable the separation of several sets of dentures belonging to the same individual according to time of construction. This would be helpful in both primary and secondary care clinical settings. Weissenstein first proposed that dentures should have some form of identifiable marking in 1931. ${ }^{3}$ To some extent, DNA analysis has made odontological post-mortem analysis superfluous. Nevertheless, inclusion of markings in removable prostheses allows rapid identification in almost all circumstances and is still mandatory practice in all branches of the UK military dental corps. ${ }^{4}$

The ideal characteristics of denture markers were initially described by Vestermark in 1975. These criteria included: 1) specific marking that is capable of rapidly yielding identification; 2) the marking process should be simple, quick and inexpensive to carry out; 3) the marking should be fire resistant, and/or placed in the posterior aspect of the palate, where retardation of incineration by tissue mass is maximal; 4) marking should not significantly weaken the removable prosthesis; and 5) identification marking should have aesthetics acceptable to the individual patient. Various examples of specific identification have been proposed, for example, the use of a national identity number containing date of birth and country of origin. ${ }^{5}$ Such marking is mandatory for all new partial and complete removable prostheses constructed in Sweden. ${ }^{6}$ There is a multitude of proposed methods for denture identification 
marking. These can broadly be classified into two principal types: surface identifiers and inclusion methods. ${ }^{7}$

Surface identifiers involve marking of the external surface of the prosthesis. Engraving of the master cast will produce embossed lettering or marking on the denture. Conversely, engraving of the fabricated prosthesis will result in countersunk marking. ${ }^{8}$ Carbon paper has also been utilised to colour the acrylic surface with lettering immediately prior to processing. As a temporary technique, patient details may be written on the surface of a processed denture using a 'permanent' marker pen. However, surface marking is vulnerable to accidental or deliberate removal. Indeed, to cope with long-term usage of a prosthesis combined with the adverse cleaning habits employed by many denture wearers, the application of $0.5 \mathrm{~mm}$ acrylic resin coverage is recommended over a surface marker. ${ }^{5}$

Due to the potential for physical or chemical degradation of surface markers, denture identification has also been incorporated deeper within the bulk of the denture acrylic using inclusion methods. Following denture construction, a recess may be cut within the denture base, an identifying wafer or label subsequently placed, and the surface replaced and sealed with self-curing acrylic. Alternatively, an identifier may be included in the base plate, immediately prior to packing and processing. Tracing paper, ${ }^{9}$ polyethylene tape, ${ }^{10}$ stainless steel ${ }^{11}$ and micro-labelling ${ }^{12,13}$ have all been advocated as appropriate materials for use as included identifiers. The use of specific metal markers has been advocated in relation to their ability to withstand high temperatures. ${ }^{14}$ More recently, microchips have been suggested as an alternative means of marking. ${ }^{14}$ These have been promoted due to the benefits in automated reading of the marker and the volume of information that can be stored in such a device.

In the United States of America, the labelling of removable prostheses is regulated by legislation in 21 states..$^{15}$ Denture identification is also compulsory for removable prostheses fabricated in Iceland and Sweden. ${ }^{6}$ Furthermore, the American ${ }^{15}$ and Australian Dental Associations ${ }^{16}$ also recommend denture identification marking for newly constructed dentures. However, within the UK, there are no specific guidelines available in relation to civilian denture marking.

Although publications have reported the views of individuals with regard to denture marking, ${ }^{12}$ no studies have investigated the wide held views of those dentists whose clinical practice is substantially involved with the provision of removable prostheses. Therefore, the aims of this study were to assess the attitudes of UK prosthodontic specialists to denture identification marking and to provide an insight into the quantity of denture marking currently undertaken by the dental profession and by other healthcare workers. In order to achieve this, two groups were surveyed by postal questionnaires. These comprised prosthodontic/restorative specialists registered with the UK General Dental Council (GDC) and residential care staff responsible for overseeing the oral health of their population.

\section{METHOD}

Questionnaires were sent to a sample of GDC-registered prosthodontic specialists practising throughout the UK and carers in nursing homes within the greater Glasgow area. Following initial discussion and testing of pilot questionnaires, it was decided that differing questionnaires would be issued to

\begin{tabular}{|c|c|}
\hline & Gender: \\
\hline 2. & Year of qualification: \\
\hline 3. & University qualified from: \\
\hline \multicolumn{2}{|r|}{ 4. Within which sector do you practice? } \\
\hline$\square$ & Predominantly private (GDP) \\
\hline$\square$ & Predominantly NHS (GDP) \\
\hline$\square$ & Predominantly hospital \\
\hline$\square$ & University \\
\hline$\square$ & Community \\
\hline$\square$ & Armed Forces \\
\hline$\square$ & Other \\
\hline 5. & Are you a consultant in prosthodontics? \\
\hline 6. & Within your practice is complete denture marking undertaken? \\
\hline 7. & Within your practice is partial denture marking undertaken? \\
\hline 8. & Do you feel that denture marking is a worthwhile process? \\
\hline 9. & $\begin{array}{l}\text { Do you think that guidelines are necessary to promote denture marking } \\
\text { within the UK? }\end{array}$ \\
\hline 10. & Please write any comments you may have on the use of denture marking \\
\hline 11. & How much of your time is spent on the care of institutionalised patients? \\
\hline$\square$ & Considerable \\
\hline$\square$ & Moderate \\
\hline$\square$ & Minimal \\
\hline$\square$ & None \\
\hline
\end{tabular}

\begin{tabular}{|c|c|c|c|}
\hline & YES & NO & UNSURE \\
\hline $\begin{array}{l}\text { Is complete denture marking } \\
\text { undertaken in your practice? }\end{array}$ & $\begin{array}{l}54.9 \% \\
(n=64)\end{array}$ & $\begin{array}{l}44.2 \% \\
(n=51)\end{array}$ & $\begin{array}{l}0.9 \% \\
(n=1)\end{array}$ \\
\hline $\begin{array}{l}\text { Is partial denture marking } \\
\text { undertaken in your practice? }\end{array}$ & $\begin{array}{l}40.9 \% \\
(n=47)\end{array}$ & $\begin{array}{l}58.3 \% \\
(n=68)\end{array}$ & $\begin{array}{l}0.9 \% \\
(n=1)\end{array}$ \\
\hline Is denture marking worthwhile? & $\begin{array}{l}81.0 \% \\
(n=94)\end{array}$ & $\begin{array}{l}11.2 \% \\
(n=13)\end{array}$ & $\begin{array}{l}7.6 \% \\
(n=9)\end{array}$ \\
\hline $\begin{array}{l}\text { Are guidelines necessary for denture } \\
\text { identification marking in the UK? }\end{array}$ & $\begin{array}{l}68.9 \% \\
(n=80)\end{array}$ & $\begin{array}{l}23.5 \% \\
(n=27)\end{array}$ & $\begin{array}{l}7.6 \% \\
(n=9)\end{array}$ \\
\hline
\end{tabular}

prosthodontic specialists and nursing home carers. Questionnaires would also be kept concise and primarily comprise limited option tick-boxes. However, individual comments on denture identification in general and on any favoured marking method were also recorded. Questionnaires were used to collect information on each respondent's background, experience and relevant attitudes to denture identification marking.

At the time of data collection, 374 individuals were registered with the UK General Dental Council as specialists in 
Table 3 Effect of the predominant clinical practice upon denture marking procedures used by specialists in prosthodontics

\begin{tabular}{|c|c|c|c|c|c|c|}
\hline \multirow{2}{*}{ Working environment } & \multicolumn{3}{|c|}{ Is complete denture marking carried out in your practice? } & \multicolumn{3}{|c|}{ Is partial denture marking carried out in your practice? } \\
\hline & Yes & No & Don't know & Yes & No & Don't know \\
\hline $\begin{array}{l}\text { Community/Salaried } \\
\text { dental service }\end{array}$ & $\begin{array}{l}88.9 \% \\
(n=8 ; p=0.035)\end{array}$ & $\begin{array}{l}11.1 \% \\
(n=1)\end{array}$ & $\begin{array}{l}0 \% \\
(n=0)\end{array}$ & $\begin{array}{l}55.6 \% \\
(n=5)\end{array}$ & $\begin{array}{l}44.4 \% \\
(n=4)\end{array}$ & $\begin{array}{l}0 \% \\
(n=0)\end{array}$ \\
\hline Armed Forces & $\begin{array}{l}100 \% \\
(n=9 ; p<0.001)\end{array}$ & $\begin{array}{l}0 \% \\
(n=0 ; p=0.005)\end{array}$ & $\begin{array}{l}0 \% \\
(n=0)\end{array}$ & $\begin{array}{l}100 \% \\
(n=9)\end{array}$ & $\begin{array}{l}0 \% \\
(n=0)\end{array}$ & $\begin{array}{l}0 \% \\
(n=0)\end{array}$ \\
\hline Hospital/University & $\begin{array}{l}50.0 \% \\
(n=23)\end{array}$ & $\begin{array}{l}47.8 \% \\
(n=22)\end{array}$ & $\begin{array}{l}2.2 \% \\
(n=1)\end{array}$ & $\begin{array}{l}37.8 \% \\
(n=17)\end{array}$ & $\begin{array}{l}60.0 \% \\
(n=27)\end{array}$ & $\begin{array}{l}2.2 \% \\
(n=1)\end{array}$ \\
\hline Practice (NHS and/or private) & $\begin{array}{l}46.1 \% \\
(n=24)\end{array}$ & $\begin{array}{l}53.9 \% \\
(n=28)\end{array}$ & $\begin{array}{l}0 \% \\
(n=0)\end{array}$ & $\begin{array}{l}30.2 \% \\
(n=16)\end{array}$ & $\begin{array}{l}69.8 \% \\
(n=37)\end{array}$ & $\begin{array}{l}0 \% \\
(n=0)\end{array}$ \\
\hline
\end{tabular}

fixed and removable prosthodontics. This group comprised dentists either being registered as a monospecialist or specialist within restorative dentistry. Study participants were quasi-randomly recruited by selecting alternate prosthodontists on the specialist list until 160 individuals were recruited. Questionnaire A was sent to these individuals at their given address for specialist registration, including a reply paid and addressed envelope for ease of return (Table 1). To evaluate knowledge and attitudes of nursing staff and managers of long stay nursing homes for the elderly within the Glasgow region, telephone interviews were undertaken. Initially, a questionnaire was sent out to nursing homes responsible for the care of the elderly combined with a covering letter explaining the rationale of the study. Subsequently, nursing staff (n $=58$ ) within these care homes were contacted by telephone to determine their current practice of looking after elderly patients with removable prostheses. A record was made as to whether they made use of denture identification procedures of any form or not.

Statistical analysis was carried out using the Chi square test using Minitab software (Minitab Inc, USA). Results with a $p$ value $<0.05$ were considered as statistically significant.

\section{RESULTS}

Specialists in prosthodontics

One hundred and nineteen of the 160 questionnaires (74\%) distributed to specialists in prosthodontics were returned. of these, three were returned incomplete and excluded from the study, thereby allowing complete data analysis of 116 questionnaires.

Results from questions enquiring about the quantity of denture marking undertaken by the prosthodontic specialists and their opinion as to the benefit of prosthesis marking are displayed in Table 2. Of importance, $81 \%$ of specialists who returned the questionnaire determined that denture identification marking was a worthwhile procedure.

The majority of surveyed prosthodontic specialists spent nil $(42.1 \%)$ or only a minimal $(46.5 \%)$ amount of their clinical time caring for institutionalised patients (Figure 1). Interestingly, all specialists who responded to the questionnaire indicating that a considerable amount of their time was involved in the clinical care of institutionalised patients worked within the community dental service.

The questionnaire survey incorporated responses from specialists working within a broad range of clinical dental practice environments (Figure 2). The responses demonstrated a high prevalence of denture marking being undertaken within the community dental service and UK Armed Forces. Of the surveyed specialists based within the community dental service, 88.9\% carried out marking of complete dentures, significantly more than the wider body of prosthodontic specialists $(p=0.035)$. Similarly, all of the specialists who practiced in the Armed Forces undertook complete denture marking $(\mathrm{p}=0.05$, $\mathrm{n}=9$ ) as displayed in Table 3 .

Of the 64 specialists who did mark complete dentures, 93.7\% of those determined that it was a worthwhile procedure ( $\mathrm{p}=$ $0.05, \mathrm{n}=60$ ). Similarly, of the 47 specialists who routinely prescribed partial denture marking, 95.6\% expressed the view that denture marking was a worthwhile exercise $(\mathrm{p}=0.04, \mathrm{n}=$ 45). Ninety-four prosthodontic specialists considered denture identification marking worthwhile, and of these respondents, $82.1 \%$ indicated that they would welcome the introduction of some sort of guideline for denture marking ( $\mathrm{p}<0.01, \mathrm{n}=80$ ). The results imply a strong association between specialists' opinion on the worth of removable prosthesis marking and the perceived need for regulatory guidelines on the practice.

\section{Nursing care staff}

Following receipt of postal questionnaires, 58 telephone interviews were undertaken to assess the knowledge and attitudes of nursing staff and managers within long stay nursing homes responsible for care of the elderly within the surrounds of Glasgow. This was devised to assess procedures in relation to a best practice statement on denture and oral care. From the telephone interviews, not one carer mentioned denture marking as a feature of the care of their patients who wore removable prostheses.

\section{DISCUSSION}

The response rate of questionnaires sent to prosthodontic specialists was high with 119 of the 160 (74.4\%) posted questionnaires being completed and returned. This likely demonstrates the importance attached to denture identification marking by specialists in prosthodontics. This is corroborated by the fact that $49 \%$ of prosthodontic specialists who completed and returned questionnaires took the time to write additional comments expressing their personal views related to denture marking. The majority of statements were supportive of the need to undertake an identification procedure. One specialist prosthodontist stated that 'It is absolutely essential to mark acrylic removable partial dentures and complete dentures' and another that denture marking 'should be mandatory'. Indeed, 


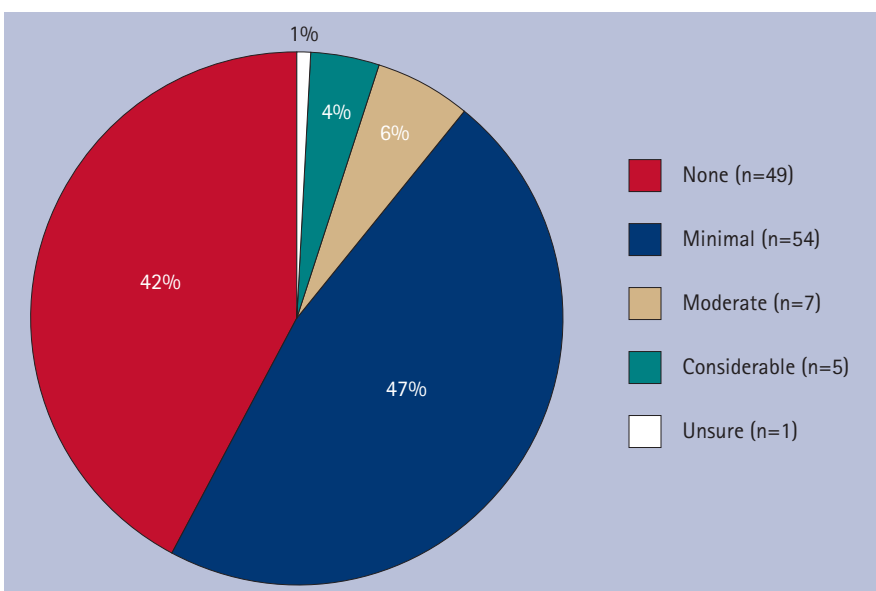

Fig. 1 Pie chart demonstrating the time surveyed specialists spent caring for institutionalised patients

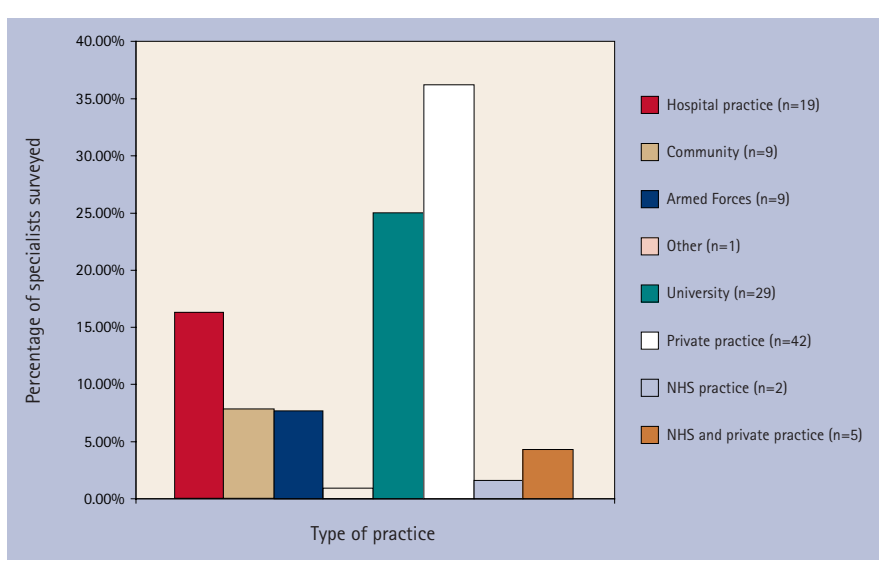

Fig. 2 Bar chart demonstrating surveyed specialists' principal type of practice

the results demonstrate that the overwhelming majority (81\%) of specialist prosthodontists surveyed considered denture marking to be a worthwhile procedure. Given this substantial support, it is surprising that only 55\% of surveyed specialists routinely marked complete dentures. Moreover, only $41 \%$ routinely marked partial removable prostheses. Hence, there is a discrepancy between opinion on best practice and actual clinical practice.

Interestingly, those prosthodontic specialists who indicated that they devoted a considerable quantity of their clinical time to working with institutionalised patients all prescribed the marking of complete dentures. However, only 56\% of specialists with little or no clinical involvement in the treatment of institutionalised patients undertook denture marking. With regard to the care of institutionalised patients, the returned questionnaires revealed some interesting comments. One specialist expressed the opinion that 'It should be mandatory, as a house officer I spent many happy hours trying to sort out dentures nurses had decided to clean in one big sink!'

It is therefore of interest that a BDA key issue policy paper entitled Oral healthcare for older people: 2020 vision $^{17}$ recommends the marking of existing dentures for easy identification in residential homes. It also advises that the marking of removable prostheses should be available, free of charge, to NHS patients. More recently, NHS Quality Improvement Scotland (NHS QIS) released the best practice statement Working with dependent older people to achieve good oral health in May 2005.
This guidance was established from evidence derived from audit, research, patient surveys and expert opinion. The document aims to encourage a 'consistent and cohesive' approach to oral care of the elderly. It is primarily targeted at registered nurses that have responsibility for implementation of oral care of this population group at local level. The 'Evidence-based protocol for daily oral care', which forms part of the best practice statement, specifically states in the section relating to care of the edentulous patient with dentures, that nursing staff should 'ensure that dentures are marked with the person's name (eg “Identure” Denture Marking System, Geri Incorporated)'.

Given the evidence and expert opinion that institutionalised patients would particularly benefit from denture identification, it is particularly concerning that prosthesis marking was not undertaken by any of the carers involved in the study. This is, however, in accordance with other recent studies which highlight deficiencies in healthcare professionals' knowledge of appropriate healthcare regimes for elderly patients. ${ }^{18}$ Indeed, overall oral healthcare provision for this patient cohort was found to be suboptimal (manuscript in preparation).

It is evident that despite the opinion of prosthodontists and those dentists involved in the oral care of institutionalised elderly populations, denture identification marking is rarely, if ever, undertaken. This is in stark contrast to clinical practice in Sweden where a study carried out by Bengtsson et al. established that 50\% of dentures in elderly people's homes in Gothenberg were marked..$^{19}$ Furthermore, the UK Alzheimer's Society advises that newly constructed removable prostheses should be permanently marked during their manufacture. ${ }^{20}$ It is therefore apparent that the dental profession and associated professional societies need to provide clearer guidance as to the benefits and specific requirements of denture marking.

It could be argued that denture marking is only of significant benefit to those in residential or nursing care to prevent the mix up of removable prostheses. Indeed, one specialist prosthodontist commented, 'I can see their value in the institutionalised patient but is of little relevance for the ordinary situation'. Nevertheless, with an ageing population, a healthy patient may have removable prostheses fabricated whilst able to attend a general dental practitioner but may subsequently enter institutionalised care where an identification marker on their prosthesis would be beneficial. Also, if a patient owns several sets of dentures, it is often useful for both dentist and patient to match the upper and lower of a pair, or to place the sets in sequence. Of additional importance, post-mortem identification of human bodies can be undertaken using dentures. Therefore, forensic dental specialists advise identification marking of removable prostheses. ${ }^{9}$

Prior to the introduction of the new dental contract in England and Wales, there was an additional fee for inclusion of a permanent patient identification marker in a denture on the NHS fee per item scale. Information provided from the Dental Practice Board for England and Wales establishes that in 2004/2005, 464,918 claims were made for the provision of acrylic removable prostheses. This figure comprises both complete and partial prostheses. However, only 31,829 claims were lodged for the additional fee for an identification marker. Therefore, only $6.8 \%$ of fabricated removable prostheses were apparently marked for identification purposes. ${ }^{21}$ Statistics available from the Scottish Dental Practice Board reveal 
similar findings. During 2004, there were 136,215 claims for partial and complete removable dentures. Conversely, only 5,106 claims were made for an identification marker, representing only $3.75 \%$ of fabricated removable prostheses. These figures clearly demonstrate the very low prevalence of denture identification marking currently undertaken by dentists within the UK. Indeed, a recent audit of patients with complete dentures referred to Glasgow Dental School and Hospital determined that only $2 \%$ of consecutive complete removable prostheses carried any form of identification labelling (S. Dhar, unpublished observations).

There may be some important barriers to the wide-scale marking of removable prostheses. Importantly, identification marking of dentures will involve the patient's consent and some patients may object to their details being marked on their denture, effectively labelling the individual. Such attitudes and concerns to denture marking were also expressed by a small number of specialists. One specialist commented that $\mathrm{s} / \mathrm{he}$ 'can see a reason for this in the armed forces personnel but if you are really keen on bar coding/branding people do look at the civil liberties issue'. Naturally, in view of civil liberties, it is acknowledged that the patient may decline the use of denture marking. One specialist who was surveyed in our study commented on this, indicating the importance of patient choice: 'There are $a$ minority of patients who do not wish to have their dentures labelled, is it good practice to counter patients' wishes?'

Previous studies have demonstrated that the proportions of patients who express this opinion once the benefits of the procedure are explained to them are very small. ${ }^{7}$ Nevertheless, if mandatory guidelines on denture marking were to be formulated and instigated, a patient would have to be given the option to decline the marking of their new denture(s). A further comment raised by a few specialists opposed to the introduction of denture marking guidelines was that the number of guidelines already produced for clinical practice was too large. Such individuals advised that denture identification guidelines would merely add to the current substantial number. Indeed, one specialist remarked 'please no more guidelines'. This may account for the fact that the proportion of specialists who thought that guidelines for denture marking were necessary was lower than the proportion who thought denture marking was a worthwhile process. Such comments indicate the need for any recommendations and guidelines to be kept as precise and straightforward as possible. Therefore, if guidelines were introduced to establish the marking of dentures as a routine laboratory procedure by dental technicians, this may obviate the necessity to introduce further guidelines to clinicians. Dentists or clinical dental technicians would be left with the simple task of advising the laboratory of not marking the prosthesis, should the patient decline. Alternatively, unsolicited marking could be restricted to methods that are reversible or where the information may be erased.

\section{CONCLUSIONS}

There are several advantages to the placement of identifying marks on removable prostheses. These advantages relate to the care of the patient, the provision of oral healthcare within residential care homes, the care of patients within the general dental services and in forensic identification. Although these apply to both partial and complete dentures, partial dentures are more individual and distinct by their nature. Therefore, the added value of identification applies particularly to complete removable dentures. The overwhelming opinion of surveyed prosthodontic specialists in the UK is that denture marking should be provided on a routine basis. In summary, it would seem appropriate that guidelines be constructed within the UK in order to encourage the benefit of denture marking in the most suitable way for different patients in different circumstances. Indeed, these guidelines could be directly introduced at the point of denture fabrication, within the dental laboratory.

1. Mojon $P$, Thomason J M, Walls A W G. The impact of falling rates of edentulism. Int J Prosthodont 2004: 17: 434-440.

2. Kelly M, Steele J, Nuttall N et al. Adult dental health survey: oral health in the United Kingdom 1998. London: The Stationery Office, 2000.

3. Fletcher A M, Turner $\mathrm{CH}$, Ritchie G M. Denture marking methods and induced stress. Br Dent J 1977; 142: 224-226.

4. Fletcher $A M$, Turner $C H$, Ritchie $G$ M. Denture marking and human identification. BrDent J 1976; 141: 114-117.

5. Thomas $C J$. The role of the denture in identification: a review. J Forensic Odontostomatol 1984; 2 : 13-16.

6. Borrman H I M, DiZinno J A, Wasen J, Rene N. On denture marking. J Forensic Odontostomatol 1999: 17: 20-26.

7. Cunningham $M$, Hoad-Reddick G. Attitudes to identification of dentures: the patients perspective. Quintessence Int 1993; 24: 267-269.

8. Ling B C, Nambiar P, Low K S, Lee C K. Copper vapour laser ID labelling on metal dentures and restorations. J Forensic Odontostomatol 2003; 21: 17-22.

9. Pretty I A, Sweet D. A look at forensic dentistry - part 1: the role of teeth in the determination of human identity. Br Dent J 2001; 190: 359-366.

10. Matsumura $H$, Shimoe $S$. Incorporation of a cast, embossed identification plate into a partial denture framework. J Prosthet Dent 2002; 88: 215-217.

11. Reeson M G. A simple and inexpensive inclusion technique for denture identification. J Prosthet Dent 2001; 86: 441-442.

12. Ibrahim W M A. Denture microlabelling technique. J Prosthet Dent 1996; 76: 104.

13. Ling B C. Computer-printer denture microlabelling system. J Prosthet Dent 1998 ; 79: 363-364.

14. Millet $\mathrm{C}$, Jeannin $\mathrm{C}$. Incorporation of microchips to facilitate denture identification by radio frequency tagging. J Prosthet Dent 2004; 92: 588-590.

15. American Dental Association Council on Dental Practice. The dentist's role in forensic identification: the release of dental records \& radiographs, and denture labelling. ADA policy report. Chicago: American Dental Association, 2004.

16. Alexander P M V, Taylor J A, Szuster F S P, Brown K A. An assessment of attitudes to, and extent of, the practice of denture marking in South Australia. Aust Dent J 1998: 43: 337-341.

17. British Dental Association. Oral healthcare for older people: 2020 vision. BDA key issue policy paper. London: British Dental Association, 2003.

18. Preston A J, Kearns A, Barber M W, Gosney M A. The knowledge of healthcare professionals regarding elderly persons' oral care. Br Dent J 2006; 201: 293-295.

19. Bengtsson A, Olsson T, Rene N, Dahlbom U, Carlsson G E, Borrman H. Frequency of identification marking of removable dentures in long term care units in Sweden. J Oral Rehabil 1996; 23: 520-523.

20. Alzheimer's Society. Dental care and dementia. Alzheimer's Society information sheet. London: Alzheimer's Society, 2003. www.alzheimers.org.uk/Caring_for_ someone_with_dementia/Health/advice_dental.htm

21. NHS Business Services Authority Dental Practice Division website. www.dpb.nhs.uk. 